Abstract 128 Table 1 Patients characteristics and associations with LSI by disease duration, at baseline

\begin{tabular}{|c|c|c|c|}
\hline \multirow{2}{*}{$\begin{array}{l}\text { Variables * } \\
\text { Patient's characteristics }\end{array}$} & \multirow{2}{*}{$\begin{array}{l}\text { Descriptive } \\
\text { Statistics ** }\end{array}$} & \multicolumn{2}{|c|}{ Association with LSI *** } \\
\hline & & Incident cases & Prevalent cases \\
\hline Age & $\begin{array}{l}49.0 \\
(36.8-58.5)\end{array}$ & $-0.19(p=0.028)$ & $-0.19(p=<0.001)$ \\
\hline Gender & & $p=0.007$ & $p=0.006$ \\
\hline Women & $589(92)$ & $5.4(4.9-6.3)$ & $6.3(5.7-8.0)$ \\
\hline Men & $55(9)$ & $6.7(5.6-8.3)$ & $7.1(5.8-8.5)$ \\
\hline Ethnicity ( $n=592)$ & & $p=0.032$ & $p=0.005$ \\
\hline Caucasian & $437(74)$ & $5.4(4.7-6.4)$ & $5.7(5.1-7.9)$ \\
\hline Asian & $80(14)$ & $6.1(5.4-8.5)$ & $7.7(5.3-8.2)$ \\
\hline Other & $75(13)$ & $5.9(5.3-8.1)$ & $5.9(5.2-8.2)$ \\
\hline Marital Status $(n=586)$ & & $p=0.318$ & $p=0.076$ \\
\hline Single & $107(18)$ & $5.7(5.3-7.3)$ & $6.5(5.3-8.2)$ \\
\hline Married & $387(66)$ & $5.4(4.7-6.3)$ & $5.8(5.2-8.0)$ \\
\hline Other & $92(16)$ & $5.4(4.8-7.1)$ & $5.7(4.9-8.2)$ \\
\hline Site & & $p=0.789$ & $p=0.383$ \\
\hline Winnipeg & $231(36)$ & $5.8(4.9-7.0)$ & $5.6(5.0-7.8)$ \\
\hline Hamilton & $25(4)$ & $6.2(5.4-6.6)$ & $6.6(5.4-7.1)$ \\
\hline Quebec & $129(20)$ & $5.4(4.6-6.8)$ & $6.2(5.2-8.3)$ \\
\hline Ottawa & $4(1)$ & $6.1(6.1-6.1)$ & $6.3(5.7-8.2)$ \\
\hline London & $6(1)$ & $7.2(7.2-7.2)$ & $6.1(5.5-7.8)$ \\
\hline Calgary & $244(38)$ & $5.4(5.0-6.3)$ & $5.9(5.1-8.1)$ \\
\hline \multicolumn{4}{|l|}{ Disease's characteristics } \\
\hline Disease duration $(n=623)$ & $10.1(2.7-20.6)$ & $0.11(p=0.241)$ & $0.07(p=0.106)$ \\
\hline Recent diagnosis ( $<=15$ months) & & NC & NC \\
\hline \multicolumn{4}{|l|}{ Ancient diagnosis (>15 months) } \\
\hline ACR Criteria Score $(n=626)$ & $5(4-6)$ & $0.29(p<0.001)$ & $0.30(p<0.001)$ \\
\hline ACR LSI Score $(n=626)$ & $5.8(5.1-7.9)$ & NC & NC \\
\hline SLICC Criteria Score $(n=538)$ & $6(5-8)$ & $0.49(p<0.001)$ & $0.42(p<0.001)$ \\
\hline SLEDAI score $(\mathrm{n}=598)$ & $2(0-6)$ & $0.05(p=0.586)$ & $-0.00(p=0.992)$ \\
\hline SLAQ Score $(n=407)$ & $12(7-18)$ & $-0.26(p=0.023)$ & $-0.18(p=0.001)$ \\
\hline SDI Score $(n=609)$ & $0(0-2)$ & $p=0.296$ & $p=0.005$ \\
\hline 0 & $310(51)$ & $5.5(4.8-6.4)$ & $5.6(4.9-7.9)$ \\
\hline$>0$ & $299(49)$ & $5.5(5.2-8.0)$ & $6.2(5.2-8.2)$ \\
\hline \multicolumn{4}{|l|}{ Medication } \\
\hline Prednisone $(n=614)$ & & $\mathrm{p}<0.001$ & $\mathrm{p}<0.001$ \\
\hline Yes & $203(33)$ & $6.4(5.3-8.2)$ & $6.8(5.5-8.2)$ \\
\hline No & $411(67)$ & $5.4(4.7-6.0)$ & $5.6(4.9-7.7)$ \\
\hline Prednisone dose $(n=219)$ & $7.5(5.0-15.0)$ & $0.41(p=0.001)$ & $-0.01(p=0.92)$ \\
\hline Imunomodulators $(n=616)$ & & $\mathrm{p}=0.189$ & $p=0.028$ \\
\hline Yes & $554(90)$ & $5.5(5.0-6.9)$ & $5.9(5.2-8.1)$ \\
\hline No & $62(10)$ & $5.3(4.4-6.2)$ & $5.5(4.9-6.4)$ \\
\hline Antimalarial & & $\mathrm{p}=0.241$ & $\mathrm{p}=0.97$ \\
\hline Yes & $517(83)$ & $5.5(4.9-6.8)$ & $5.8(5.1-8.1)$ \\
\hline No & $106(17)$ & $5.2(4.6-6.3)$ & $5.8(4.9-8.2)$ \\
\hline Biologic Agent $(n=609)$ & & $p=0.800$ & $p=0.270$ \\
\hline Yes & $25(4)$ & $5.9(5.3-6.5)$ & $6.1(5.3-8.4)$ \\
\hline No & $584(96)$ & $5.5(4.9-6.8)$ & $5.8(5.1-8.1)$ \\
\hline Death during follow-up & & NC & $p=0.002$ \\
\hline Yes & $12(2)$ & & $8.2(7.0-9.3)$ \\
\hline No & $627(98)$ & & $5.8(5.1-8.1)$ \\
\hline
\end{tabular}

${ }^{*} \mathrm{n}=639$ except when specified; ${ }^{*}$ Results presented as Median (1 st quartile 3rd quartile) or Frequency (percentage) for continuous and categorical variables respectively; ${ }^{* * *}$ Results presented as Spearman Correlation coefficient (pvalue) or Median (1 st quartile 3rd quartile) with Kruskal-Wallis pvalue for continuous and categorical variables respectively; NC: Not calculated. like disease activity and prednisone dose - modifiable. LSI can predict adverse outcome such as damage or death over time. Funding Source(s): Lupus Canada.

\section{MACROPHAGE ACTIVATION SYNDROME AS A PRESENTATION IN PEDIATRIC LUPUS: A RETROSPECTIVE STUDY OF 3 CASES}

${ }^{1}$ Ankita Singh* ${ }^{2}$ Rakesh Pilania, ${ }^{1}$ Sandesh Guleria, ${ }^{2}$ Nameirakpam Johnson, ${ }^{2}$ Gummadi Anjani, ${ }^{1}$ Ankur Jindal, ${ }^{2}$ Pandiarajan Vignesh, ${ }^{1}$ Deepti Suri, 'Surjit Singh. ${ }^{1}$ Postgraduate Institute of Medical Education and Research, Chandigarh, India; ${ }^{2}$ Dept. of Pediatrics, Allergy- Immunology Unit, Postgraduate Institute of Medical Education and Research

\subsection{6/lupus-2019-Ism.129}

Background Macrophage activation syndrome (MAS) can, at times, be the presentation of pediatric lupus and diagnosis requires high index of suspicion.

Methods We retrospectively studied 140 pediatric lupus patients from January 1993- November 2018 and collected clinical and laboratory data of patients (3) who had MAS as presenting manifestation.

Results Case 1 was 11-year-old girl with fever for 4 months associated with rash and generalized body swelling for 1 month. Examination revealed rash over malar area and ear lobules, anasarca, hepatomegaly, bilateral pleural and pericardial effusion. In view of multisystem involvement a possibility of lupus was considered which was confirmed by investigations (table 1). She had elevated ferritin and fasting triglyceride and low fibrinogen. A clinical possibility of lupus with associated MAS was considered. She received pulses of methylprednisolone, one dose of intravenous immunoglobulin following which she improved. In view of nephrotic range proteinuria she was started on induction regimen with cyclophosphamide and shifted to mycophenolate in maintenance. Her initial SLEDAI-2k was 32- this decreased to 4 at 3 year follow-up.

Case 2 was a 9-year-old girl with fever, rash, generalized body swelling for 1 month and altered sensorium for 4 days. Examination revealed pallor, oral ulcers and hepatomegaly. She was in shock at presentation. In view of multisystem involvement a possibility of lupus was considered which was confirmed by investigations (table 1). She had pericardial effusion and low ejection fraction (25\%). A possibility of MAS was considered and investigations revealed hyperferritinemia, elevated triglyceride and hypofibrinoginemia. She was given methylprednisolone pulses and continued on oral prednisolone, mycophenolate and hydroxychloroquine. Her initial SLEDAI$2 \mathrm{k}$ was 17 - this decreased to 0 at 3 year follow-up.

Case 3 was an 8-year-old girl who had fever, rash and body swelling for 15 days. She had tachycardia, tachypnea, pallor, anasarca, subconjunctival bleed and frontal alopecia. She had pleural and pericardial effusion. In view of multisystem involvement a possibility of lupus was considered which was confirmed by investigations (table1). She had high ferritin and triglyceride. So a possibility of MAS was considered and she received pulse methyl prednisolone and intravenous immunoglobulin. She also had hematuria and proteinuria (renal biopsy could not be performed as she was sick and had thrombocytopenia) so was given pulse cyclophosphamide 


\begin{tabular}{llll} 
Abstract 129 Table 1 & & & \\
\hline Investigations & Case 1 & Case 2 & Case 3 \\
\hline Haemoglobin (g/L) & 70 & 67 & 70 \\
White cell counts (/L) & $1.5 \times 10^{6}$ & $2.5 \times 10^{6}$ & $3.5 \times 10^{6}$ \\
Lymphocyte count (/L) & $0.4 \times 10^{6}$ & $0.6 \times 10^{6}$ & $0.8 \times 10^{6}$ \\
Platelet count (/L) & $63 \times 10^{9}$ & $50 \times 10^{9}$ & $76 \times 10^{9}$ \\
Urine protein (mg/m²/hour) & 74 & & \\
C3 (Normal 50-150 mg/dL) & $<27$ & $<27$ & $<27$ \\
C4 (Normal 20-50 mg/dL) & 4 & 3 & 3 \\
ANA (immunofluorescence method) & $4+$ diffuse & $3+$ diffuse & $4+$ diffuse \\
Anti dsDNA (N:<60 IU/mL) & 707 & 583 & 1394 \\
Serum ferritin (ng/ml) & 3233 & 6767 & 1019 \\
Fasting triglyceride (mg/dl) & 442 & 504 & 328 \\
Fibrinogen (mg/dl) & 120 & 160 & \\
\hline
\end{tabular}

followed by mycophenolate. Her initial SLEDAI-2k was 25this decreased to 0 at 2 year follow-up.

Conclusions MAS can be the presenting manifestation of pediatric lupus and may contribute to disease severity and requires aggressive management

Funding Source(s): None

\section{JUVENILE SYSTEMIC LUPUS ERYTHEMATOSUS RELATED PANCREATITIS: AN UNCOMMON MANIFESTATION OF A COMMON DISEASE}

${ }^{1}$ Gummadi Anjani*, ${ }^{2}$ Ankita Singh, ${ }^{1}$ Rakesh Pilania, ${ }^{1}$ Nameirakpam Johnson, ${ }^{1}$ Pandiarajan Vignesh, ${ }^{2}$ Deepti Suri, ${ }^{3}$ Anju Gupta, ${ }^{2}$ Ankur Jindal, ${ }^{2}$ Surjit Singh. ${ }^{1}$ Dept. of Pediatrics, Allergy- Immunology Unit, Postgraduate Institute of Medical Education and Research; ${ }^{2}$ Postgraduate Institute of Medical Education and Research, Chandigarh, India; ${ }^{3}$ PGIMER Chandigarh

\subsection{6/lupus-2019-Ism.130}

Background Pancreatitis is a rare but potentially life-threatening complication of systemic lupus erythematosus(SLE).SLErelated pancreatitis can be a presenting manifestation of SLE or may occur during follow-up.

Methods We have reviewed the clinical records of 140 children with SLE between period of 1993-2018. We report 3 children with SLE who presented with acute pancreatitis.

Results Case1-12-year-girl presented with fever and alopecia. Examination revealed pedal oedema,periorbital puffiness, large joint arthritis.Investigations showed anemia,thrombocytopenia, elevated erythrocyte sedimentation rate(ESR), normal renal functions, microscopic hematuria,nephrotic range proteinuria, hypocomplementemia,antinuclear antibody (ANA) 4+,elevated anti double stranded DNA (anti-ds DNA),negative antiphospholipid antibodies (APLA) titre(table).Renal biopsy revealed Class 3 lupus nephritis and initiated on intravenous methylprednisolone.Two days later,she developed severe epigastric pain and vomiting. The pain increased in severity and physical examination revealed marked tenderness in the epigastrium. Serum amylase and lipase were elevated.Clinical possibilities included steroid induced pancreatitis and lupus pancreatitis.In view of severity of symptoms, intravenous methylprednisolone was continued following which she showed a dramatic improvement and normalisation of pancreatic enzymes. There has been no recurrence of pancreatitis over 3 years of followup period and remained well on low dose oral prednisolone (5 mg),mycophenolate-mofetil and hydroxychloroquine.
Abstract 130 Table 1 Investigation Table

\begin{tabular}{|c|c|c|c|}
\hline Investigation & Case 1 & Case 2 & Case 3 \\
\hline Haemoglobin ( $g / L)$ & $92 \mathrm{~g} / \mathrm{L}$ & $96 \mathrm{~g} / \mathrm{L}$ & $80 \mathrm{~g} / \mathrm{L}$ \\
\hline White cell counts & $7.7 \times 10^{6} / \mathrm{L}$ & $7.8 \times 10^{6} / \mathrm{L}$ & $7.5 \times 10^{6} / \mathrm{L}$ \\
\hline \multirow[t]{2}{*}{ Lymphocyte count } & $2.15 \times 10^{6} /$ & $1.9 \times 10^{6} / \mathrm{L}$ & $1.95 \times 10^{6} /$ \\
\hline & $\mathrm{L}$ & & $\mathrm{L}$ \\
\hline \multirow[t]{2}{*}{ Platelets } & $130 \times 10^{9} /$ & $150 \times 10^{9} / \mathrm{L}$ & $420 \times 10^{9} /$ \\
\hline & $\mathrm{L}$ & & $\mathrm{L}$ \\
\hline Urine routine & $10-12$ & Few RBC, & No RBC, \\
\hline \multirow[t]{4}{*}{ Urine protein ( $\mathrm{mg} / \mathrm{m}^{2} /$ hour) } & $\mathrm{RBC}, 3$ & $3+$ albumin & 3 \\
\hline & +albumin & $82 \mathrm{mg} / \mathrm{m}^{2} / \mathrm{hr}$ & +albumin \\
\hline & & & $40 \mathrm{mg} /$ \\
\hline & & & $\mathrm{m}^{2} / \mathrm{hr}$ \\
\hline C3 (Normal 50-150 mg/dL) & 23.4 mg/ & $129 \mathrm{mg} / \mathrm{dL}$ & $34 \mathrm{mg} / \mathrm{dl}$ \\
\hline \multirow[t]{3}{*}{ C4 (Normal $20-50 \mathrm{mg} / \mathrm{dL}$ ) } & $\mathrm{dl}$ & $37 \mathrm{mg} / \mathrm{dL}$ & $10 \mathrm{mg} / \mathrm{dl}$ \\
\hline & $2.98 \mathrm{mg} /$ & & \\
\hline & $d l$ & & \\
\hline ANA & 4+diffuse & $3+$ & $3+$ diffuse \\
\hline Anti dsDNA (N:<60 IU/mL) & 890 & $<60$ & 123 \\
\hline Antiphospholipid antibodies: a) & Negative & Negative & Positive \\
\hline Lupus anticoagulant b) & Negative & Negative & Negative \\
\hline Anticardiolipin antibody (IgG and & Negative & Negative & Negative \\
\hline \multirow{2}{*}{\multicolumn{4}{|c|}{$\begin{array}{l}\operatorname{IgM}) \text { c) Anti B2 Glycoprotein -1 } \\
\text { antibody (IgG and IgM) }\end{array}$}} \\
\hline & & & \\
\hline Skin biopsy & Not done & Positivity of lupus band test & Lupus \\
\hline & & with high positive $\lg G$, $\lg A$, & band test \\
\hline & & IgM and C3 in dermal & -positive \\
\hline & & vessels & \\
\hline \multirow[t]{4}{*}{ Renal biopsy } & Class 3 & $\lg G, \lg A, \lg M$ positivity in & Class 4 \\
\hline & lupus & the mesangium as well as & lupus \\
\hline & nephritis & capillary loops and C3 in & nephritis \\
\hline & & small sized blood vessels & \\
\hline Serum amylase $(<100 \mathrm{U} / \mathrm{L})$ & $238 \mathrm{U} / \mathrm{L}$ & $400 \mathrm{U} / \mathrm{L}$ & $290 \mathrm{U} / \mathrm{L}$ \\
\hline Serum lipase $(<60 \mathrm{U} / \mathrm{L})$ & $231 \mathrm{U} / \mathrm{L}$ & Not done & Not done \\
\hline
\end{tabular}

Case2-A-6-year-old presented with pain abdomen and vomiting.Physical examination showed epigastric tenderness.Investigations showed anemia,thrombocytopenia,elevated amylase levels(table).Computerised tomography(CT) abdomen revealed acute necrotising pancreatitis.A follow-up ultrasound abdomen revealed a pancreatic pseudocyst.He had a second episode of acute pancreatitis along with anasarca after 3 months which improved with conservative management.Investigation showed anemia,nephrotic range proteinuria and microscopic haematuria(table).ANA was positive with normal complement levels and negative anti-dsDNA titres(table).Lupus band test on skin biopsy was positive. Renal biopsy showed mesangioproliferativeglomerulonephritis with full house pattern.Following the initiation of steroids, he improved and there has been no recurrence of pancreatitis over the next 4 years.

Case 3-9 year-girl presented with generalised rash,alopecia for 5 months.She also had pain abdomen for last 2 months. Investigations showed elevated amylase,ultrasound abdomen revealed acute pancreatitis.She had undergone a laparotomy elsewhere.Examination showed generalised pigmented rash,alopecia, periorbital puffiness, hard palatal ulcer,surgical scar on the abdomen.Investigations showed anemia, normal platelet count,elevated ESR, normal renal functions,nephrotic range proteinuria,elevated serum amylase.Ultrasound and CT abdomen revealed a pancreatic pseudocyst.A clinical possibility of SLE 